\title{
Places fortes. EL PAPER DE L'ESPAI PÚBLIC EN LES MOBILITZACIONS SOCIALS DE NOVA GENERACIÓ
}

\author{
Manuel Delgado Ruiz \\ Universitat de Barcelona (UB)
}

RESUM: Una eventual ecologia de l'acció dels moviments socials posaria de manifest com és de significativa la seva manera de manipular una determinada trama urbana per a fer palesa la seva protesta en cada moment històric. En aquest sentit, l'ús que fan del centres urbans els darrers corrents d'acció col-lectiva —el paradigma dels quals seria el $15 \mathrm{M}$ espanyol- posarien de manifest una revifalla del carrer com a escenari de i per al conflicte social, però, al mateix temps i més enllà, l'assignació d'un protagonisme especial a l'espai públic no sols com a escenari dramàtic, sinó també com a categoria política clau, associada al paper hegemònic del ciutadanisme com a ideologia de i per al canvi social a partir d'una reforma ètica del capitalisme.

Paraules clau: moviments socials, espai públic, centres urbans, conflicte, protesta, ciutadanisme.

RESUMEN: Una eventual ecología de la acción de los movimientos sociales revelaría lo significativo de su forma de manipular una determinada trama urbana para hacer patente su protesta en cada momento histórico. En este sentido, el uso que hacen de los centros urbanos las últimas corrientes de acción colectiva —el paradigma de las cuales sería el 15M español- evidenciaría un renacer de la calle como escenario de y para el conflicto social, pero al mismo tiempo y más allá, la asignación de un protagonismo especial al espacio público no sólo como escenario dramático, sino también como categoría política clave, asociada al rol hegemónico del ciudadanismo como ideología de y para el cambio social a partir de una reforma ética del capitalismo. 
Palabras clave: movimientos sociales, espacio público, centros urbanos, conflicto, protesta, ciudadanismo.

ABSTRACT: An ecology of the action of social movements could show how they have manipulated urban patterns to manifest their protest, in different meaningful ways, depending on the historical period. The use of urban centres in the latest waves of collective action-like the Spanish 15M movementmight first appear as a revival of the street as a stage of and for social conflict. But in this case, public space is not just the stage for a public drama; it is also a key political concept, associated with the hegemonic ideology of citizenism in this movement, which aims to produce social change from an ethical reform of capitalism.

KEYWORDS: social movements, public space, urban centres, conflict, protest, citizenism.

\section{I.Vers una ecologia de les mobilitzacions socials en contextos urbans}

L es ciutats han esdevingut $i$ esdevenen sovint proscenis de i per esdevenide vianants que fan ús del carrer o de la plaça per a expressar la seva insatisfacció amb la realitat que viuen. Es parla de manifestacions de protesta que, en alguns casos, deriven en disturbis, enfrontaments, aldarulls, avalots..., allò que el llenguatge oficial denomina «alteracions de l'ordre públic». En alguns casos, la vehemència d'aquestes utilitzacions excepcionals de l'espai urbà poden rebre el qualificatiu de revoltes, insurreccions i, quan assoleixen el seu objectiu d'enderrocar governs, revolucions. Aquesta mena de successos els realitzen coalicions provisionals i efímeres d'individus, gairebé sempre fins llavors desconeguts entre si, que s'apropien de determinats llocs públics per a proclamar reclamacions contra les institucions dominants en la societat en què viuen. Quan els cronistes del passat o del present mostren una ciutat assumint aquest paper ho fan de manera que els seus carrers o places poden antullar-se 
mers decorats passius sobre els quals es desenvolupen les dramatúrgies de la història o l'actualitat. En canvi, poques vegades s'ha remarcat el paper actiu que les morfologies urbanes tenen en el desenvolupament d'aquests fets, com es constitueixen en part activa dels esdeveniments, en la mesura que estimulen o inhibeixen uns determinats estils col·lectius d'actuar - al mateix temps que fan improcedents o inviables altres - i posen a disposició dels actors socials una xarxa de funcions i significats que acaben determinant totalment o parcialment el curs i les maneres del que passa o passarà.

Aquesta manca explicativa justificaria una ecologia de les alteracions vindicatives d'un paisatge urbà, una subdisciplina de les ciències socials de la ciutat que atengués no només les contestes col·lectives en si, les seves causes i conseqüències, sinó també i sobretot l'ambient físic en què es produeixen $\mathrm{i}$ en bona mesura les produeix, els entorns formals, els llocs precisos, el sentit de cada moviment: l'ordre de punts i diagrames que generen els moviments dels protestataris, una perspectiva que portés al primer pla la dimensió espacial i temporal dels espasmes i les contorsions que coneixen les ciutats amb motiu d'aquesta mena d'esdeveniments extraordinaris. Es tracta de contemplar com aquests s'adapten i adapten els nínxols físics en què tenen lloc, la manera com ho fan establint l'aptitud, l'eficàcia, la indiferència, la capacitat de simbiosi o la idoneïtat d'un determinat ecosistema, en aquest cas la retícula urbana mateixa.

Es contribuiria així a posar de manifest com l'espai urbà és sobretot espai per al conflicte, ben lluny dels supòsits que l'imaginen com una entitat estable i previsible, sotmesa a ritmes clars i ocupacions amables. Sabem que, a la mínima oportunitat, tot paisatge urbà pot convertir-se en un terreny per a tota mena de desacataments socials. L'urbs coneix en aquestes ocasions la naturalesa última de la vida social que alberga, tantes vegades construïda a força d'injustícies acumulades, d'odis, de greuges, de descontentaments, de tot aquest magma d'impaciències i anhels amb el qual pasten les ciutats la seva pròpia història. La vida urbana, en efecte, viu regularment, com complint una llei secreta, moments de i per a la irritació, s'exacerba, registra una efervescència especial que s'imposa amb claredat als somnis d'ordre i organicitat d'arquitectes i urbanistes i converteix l'obra d'aquests en escenari i instrument per a la combustió social, aquella de la qual poden 
derivar i es deriven constantment realitats espacials no fiscalitzables. Les protestes populars - al marge de quina sigui la seva causa; de banda de qualsevol valoració moral o política - sempre impliquen un desacatament d'un projecte espacial que no pot ser altra cosa que pura representació d'un ordre impossible. Tot d'una, per la causa que sigui, fusions sobrevingudes - de grans multituds que es mouen majestuosament a piquets reduïts que s'agiten d'una banda a una altra - converteixen la metròpoli en qualsevol cosa menys l'organització clara i llegible amb la qual somien els urbanistes i fan d'ella, de sobte, un ordit sobtat i esquerp, sotmès a codis desconeguts. Parlem, doncs, de territorialitzacions insubmises, actuacions col·lectives que impliquen formes altres de manipular la forma de la ciutat, creacions efímeres però en extrem enèrgiques que funcionen com expressions d'un urbanisme, una enginyeria urbana i una arquitectura alternatius als institucionalitzats.

En cadascuna de les seves cícliques convulsions socials la ciutat dramatitza el contenciós interminable entre dos models de societat urbana (López Sánchez, 1999). Un és el que encarna la ciutat burgesa, habitada idealment i en exclusiva per una classe mitjana autosatisfeta que detesta el conflicte; és més, que no el concep; una ciutat que s'emmotlla dòcil als requeriments de la fase de desenvolupament capitalista en què es troba en cada moment $\mathrm{i}$ es mostra disposada a incorporar-se a les grans dinàmiques de modernització urbana. De l'altra banda, la ciutat que fan els explotats i els exclosos; els proletaris d'ahir i —encara que no se'ls reconegui tal categoria - d'avui; les velles i les noves «classes perilloses». Aquesta darrera és la ciutat dels maltractats, dels ingovernables i dels antagonistes de classe, de gènere, d'ètnia, d'edat..., tots ells capaços de generar formes genuïnes de cultura —és a dir de formes de fer- basades en un ús intensiu del carrer i la plaça, tant en condicions ordinàries — la vida quotidiana - com excepcionals — la festa o la revolta. Xoquen dues maneres d'ocupar l'espai urbà, dues formes d'entendre'l, d'interpretar-lo, d'apropiar-se d'ell, i, d'acord amb aquesta incompatibilitat, dues accepcions de l'habitant i l'usuari: una centrada en la figura abstracta del «ciutadà», individu presumptament lliure i autoresponsable, posseït per sentiments de civilitat i animat per un esperit de compromís amb la bona marxa de la societat. De l'altra, el que des de les esferes de poder es percep com una massa permanentment inquieta $\mathrm{i}$ inquietant, composta 
per unes classes o sectors disposats en tot moment a convertir el seu espai de vida en espai de lluita i que, a la mínima, passen a transformar-se en la temuda vella figura de la «xusma» o el «populatxo».

Aquesta ecologia dels moviments socials i les mobilitzacions de protesta - moviments i mobilitzacions en un sentit literal, és a dir, el relatiu a canvis de posició en l'espai- hauria d'assumir dos grans eixos temàtics fonamentals: un centrat en els emplaçaments, un altre en els desplaçaments. El primer atendria la manera com certs espais en els quals viuen sectors socials en situació vindicativa poden esdevenir baluards des d'on expressar neguits o ràbies compartides, però també la convicció que és possible aconseguir objectius transformadors comuns. El factor estratègic és, en aquests casos, el de l'aglomeració, és a dir, l'acceleració-intensificació que en qualsevol moment poden conèixer les relacions quotidianes entre persones socialment homogeneïtzades per la seva condició subalterna (Delgado, 2006). Es tracta en aquests casos de les conseqüències directes d'un fet empíric, però determinant, com és l'existència d'un nínxol d'interacció permanentment actiu o activable. Per depauperats que fossin o siguin els espais de coincidència - els barris populars en nuclis antics, les grans concentracions d'habitatge social en perifèries urbanes - , aquests propicien un ambient estructurant, capaç de desencadenar determinades relacions socials, entre elles les associades a l'actuació col·lectiva darrere de fins compartits i viscuts com urgents.

D'aquesta lògica dels enclavaments i les implantacions, l'ecologia de les revoltes passaria a atendre la de les superfícies i els recorreguts. Interessarien ara les pràctiques ambulatòries, els senders que segueixen els protestataris per discórrer per una trama urbana i fer-la seva. Aquestes passejades corals uneixen entre si punts forts de la retícula ciutadana, llocs simbòlicament eloqüents, usant o generant autèntics senders rituals que mai trien a l'atzar els marcs que travessen. Per descomptat que tampoc són irrellevants els llocs en què se citen els estranys que van a fusionar-se durant un període limitat — les concentracions - o en els que desemboquen les protestes peripatètiques, al capdavall, variants de vegades iracundes de la desfilada o la processó. Els objectius escollits tampoc són mai arbitraris. Els congregats que acudeixen a una cita massiva o que marxen junts poden triar com desembocadura un punt considerat significatiu de la forma urbana - una plaça, per exemple-, 
però sovint poden fer-ho davant d'una instal·lació o edifici que consideren d'alguna manera interpel·lable o fins i tot ofenible com a conseqüència dels poders que se suposa que simbòlicament o realment s'amaguen a dins. Es tracta de caminades col·lectives que culminen en una mena d'assalt i presa metafòrica de la concreció espacial d'instàncies de poder que es consideren responsables d'una certa circumstància injusta. Un cop liquada en forma de concentració en un punt de partida, la unitat social generada i que s'identifica com a expressió d'un sector social afectat per un contenciós, es va obrint pas per determinats canals de la retícula urbana convinguts com pertinents, detenint-se en certs punts significatius del trajecte, per, finalment, fer-se present, al peu de la lletra, davant les portes o els murs de la concreció física dels poders considerats culpables o on s'estan produint esdeveniments en què el conglomerat humà cristal·litzat per a l'ocasió es considera involucrat a favor o en contra.

\section{El cosmopolitisme altermundista}

Cada sector social, cada país, cada ciutat, de vegades cada barri, tenen les seves maneres d'usar el carrer amb finalitats vindicatives. Les marxes de protesta estudiantils a Berlín, les manifestacions camperoles a Colòmbia o els motins a la perifèria de les ciutats angleses, per posar alguns exemples, tenen la seva idiosincràsia formal, $i$ es distingeixen de les d'idèntica temàtica a Seül, a les comarques del Ponent català o a les banlieus franceses, respectivament. D'igual manera, cada fase històrica, cada cicle de protestes té la seva pròpia forma de manipular de manera significativa la forma de la ciutat en què es produeix cada protesta. Desproveint el terme de la seva concomitància frívola, bé podríem dir que també en matèria de protestes i revoltes urbanes hi ha modes (cf. Tilly, 1978; 1995; Traugott, 2003; Favre, 1990; Fillieule, 1993; Fillieule i Tartakovsky, 2008; Champagne, 1984; Collet, 1982; 1988). Així, després d'una dècada de desmobilització — probablement derivada de la gran frustració que suposà la derrota momentània del comunisme com a projecte polític-, a partir de finals dels anys 90 i al llarg dels anys immediatament posteriors, el planeta va conèixer les grans concentracions altermundistes, que es van produir coincidint — bé podríem dir que incorporant-se d'alguna manera a la seva agenda - amb oportunitats en les quals representants dels 
poders mundials es reunien per dirimir qüestions i arribar a acords. En aquest cas, va ser la protesta la que va desenvolupar mecanismes de crítica tan globals com les potències polítiques i sobretot econòmiques que s'impugnaven (Iglesias Turrión, 2005; Tilly, 2005).

Així, en un moment i lloc determinats — unes dates, una ciutat- els poders fins aleshores invisibles de la mundialització capitalista es feien, per dir-ho així, carn entre nosaltres, assumien momentàniament forma física i ocupaven un determinat espai. De manera mecànica, energies socials diverses i disperses que l'enfrontaven, de les restes del sindicalisme de classe a corrents socials de nou tipus, decidien fer-se igualment reals, encarnar-se en una multitud que, com els reunits a la cimera, també havia acudit des de diferents punts del globus. Dues realitats que fins llavors havien existit només en el pla virtual —el poder mundial i el seu oponent, la confederació de contrapoders no menys mundials - , havien fet literalment aparició en unes determinades coordenades temporals i espacials. D'una banda, els poders planetaris, tancats en un baluard fortificat mitjançant tot tipus de barreres, barricades i piquets policials; l'altre, assetjant-les, la munió variada i internacional que carregava contra aquestes muralles intentant trencar-les i prendre a l'assalt la fortalesa dins la qual els infames conspiraven.

Les fites del cosmopolitisme altermundista són ben conegudes. El precedent serien potser les protestes contra l'aniversari del Fons Monetari Internacional a Madrid el 1995, encara que es coincideix que el nou estil l'establiren les protestes contra la cimera de 1'Organització Mundial del Comerç a Seattle al novembre de 1999. El varen seguir les peregrinacions internacionals, destinades a boicotejar reunions de l'FMI, de la Conferència de les Nacions Unides sobre Comerç i Desenvolupament, del Banc Mundial, del Fòrum Econòmic Mundial, de caps d'Estat i de govern, etc. El paradigma d'aquesta mena de protesta ens el podria prestar el cas de Gènova el 2001, on els manifestants van intentar repetidament l'assalt de la Zona Roja en què s'havien fet forts els membres del G20. En aquests casos les ciutats en les quals s'establia la cimera mundial - Göteborg, Washington, Praga, Niça, Barcelona...- eren sotmeses a autèntiques ocupacions policials i col·locades gairebé sota estats de setge, la qual cosa no impedia que acabessin convertides en veritables camps de bata1la. Potser l'última gran expressió d'aquest model d'ús rebel d'un espai urbà a 
càrrec de protestataris que acudeixen d'arreu — també d'altres països — a una cita a la qual no han estat convidats i la naturalesa de la qual denuncien, fóra Rostock al gener de 2007, en què el desplegament policial va implicar milers d'agents, es va aixecar al voltant dels llocs de trobada una tanca de diversos quilòmetres i es van dur a terme actuacions repressives «preventives» que van vorejar la legalitat constitucional alemanya. En el moment actual, o es renuncia a les ciutats per aixoplugar aquest tipus de trobades i s'escullen llocs d'accés complicat — com Davos, per exemple—, o bé es blinden fronteres, se suspenen tractats internacionals de lliure circulació o es prohibeix l'accés als centres urbans a no residents, com va passar a Canes en la cimera del G20 de novembre de 2011.

\section{Veu i poder de les places}

En una fase ulterior, a partir de finals de la dècada del 2000, la crisi econòmica ha tornat el protagonisme a les multituds locals en les grans apropiacions fusionals del carrer i la plaça, tot i que els mitjans de comunicació i les noves xarxes socials li atribueixen a aquestes mobilitzacions un tarannà igualment planetari. Una de les actuacions que més hem vist repetir-se en aquesta etapa ha estat la del setge $\mathrm{i}$ intent de presa de l'emplaçament d'un poder al qual retreu la seva responsabilitat en la situació que pateix una part o tota la població. Ja hem vist com aquest estil d'acció ja havia estat recurrent i compta amb referents històrics com poden ser la presa de la Bastilla de París en la Revolució Francesa, del Palau d'Hivern dels tsars a la Rússia de 1917 o de la seu del Comitè Central del Partit Comunista Romanès a Bucarest el desembre de 1989. No cal dir que el paper que han tingut els assalts i les ocupacions d'edificis oficials a Ucraïna els anys 2013 i 2014, pels dos bàndols en conflicte, posa de manifest com aquesta modalitat d'acció col·lectiva continua coneixent les seves darreres conseqüències com a culminació d'autèntiques revolucions socials.

L'interessant de les noves versions de l'assetjament a centres de poder com a tecnologia de protesta social, algunes de gran espectacularitat i del màxim ressò mediàtic, és que el setge simbòlic no s'aixeca sols contra seus governamentals, sinó també parlamentàries, de manera que s'entén que el 
retret col·lectiu és dirigit contra la casta política en general i el que s'impugna és la democràcia formal en si, o almenys la forma inautèntica en què es dóna el moment actual. Aquesta ofensa directa al poder legislatiu — que el crit «No ens representen!» resumeix bé- ha tingut els seus exemples en els setges a l'Alpingishús islandès al novembre de 2008; l'ocupació per treballadors públics del Capitoli de Madison, a Wisconsin, en febrer de 2011, o del de Califòrnia a Sacramento per estudiants al març de 2012, o les reeixides convocatòries d'envoltar els parlaments grec i català al juny 2011; l'espanyol al setembre 2012 o el portuguès un mes més tard.

A més del model encerclament-assalt o simulacre d'assalt, una altra tecnologia per a la protesta al carrer s'ha generalitzat en una darrera etapa de les lluites socials, amb unes implicacions la importància de les quals mereix ser subratllada: les acampades. La matriu d'aquesta forma d'usdefruitar l'espai urbà per a finalitats d'expressió col·lectiva és ben coneguda: la manifestació immòbil o concentració, és a dir, un tipus de cúmul humà que no es desplaça generant singladures per una xarxa de carrers, sinó que acut a un punt determinat per a romandre-hi durant un període de temps més o menys llarg. La modalitat que ha assolit un protagonisme especial en una darrera fase és aquella en la qual els vianants aplegats es neguen a dissoldre el quall humà que han suscitat protestant i es neguen a abandonar l'àrea en la qual es troben reunits. Aquesta modalitat pot tenir desenllaços tràgics quan les forces repressives decideixen actuar amb violència per expulsar els manifestants, com a la plaça de Tian'anmen de Pequín el 1989, però també ha aconseguit enderrocar règims, com va passar amb el de Milosevic a Iugoslàvia, incapaç de suportar la presència persistent i pacífica de ciutadans disconformes al centre de Belgrad el setembre del 2000.

El format de quedada de protesta que major difusió ha aconseguit en l'actual cicle és potser el de les acampades aixecades davant seus institucionals o en llocs emblemàtics dels centres urbans. Aquesta forma d'acció col·lectiva no és inèdita. El plantón és una forma de protesta antiga i ben estesa a tot Llatinoamèrica. Recordem, a l'Estat espanyol, el campament en pro del $0,7 \%$ de desembre 1994 a la Diagonal de Barcelona, o el dels treballadors de Sintel a la Castellana de Madrid el 2001. Ara bé, la modalitat de l'estada perllongada en un determinat indret d'alt valor simbòlic per part de contestataris va arribar 
a uns nivells màxims d'incidència $\mathrm{i}$ de valor polítics de la mà de les anomenades «revolucions de colors» a l'Europa postcomunista: la «revolució de les roses», que va forçar una sortida del poder d'Eduard Xevardnadze a Geòrgia el 2003; la «revolució taronja», impugnant l'elecció de Víktor Iúsxenko a Ucraïna l'any 2004; la «revolució de les tulipes», que va enderrocar el govern d'Askar Akàiev al Kirguizistan el 2005, o, a l'Orient Mitjà, la «revolució del cedre», que va imposar la sortida de les forces de Síria del Líban l'any 2005.

Aquest auge de modalitats de protesta basades en una ocupació dilatada en el temps d'un determinat espai urbà no es pot desvincular del descrèdit dels grans partits i sindicats històrics i del sistema parlamentari clàssic en general. Aquestes concentracions mantingudes en el temps, de vegades al llarg de mesos, han implicat esdeveniments que no eren sols escenificacions al servei d'una determinada convocatòria, sinó que han assumit el paper d'autèntics subjectes polítics. Aquest paper central atorgar a l'espai urbà en tant que tal ja s'insinuava en moviments com Reclaim the Streets en el context de l'altermundisme de principis de segle i l'hem acabat de veure de la mà, a partir de 2010, de les anomenades primaveres àrabs de Tunísia i Egipte, del moviment 15M espanyol, i seguint en bona mesura el seu model, de l'Occupy Wall Street als Estats Units; TomaLaCalle, al Perú; els indignats israelians; \#YoSoy132, a Mèxic; Passe Livre al Brasil; Movimiento de los Pingüinos, a Xile, expressions locals del que s'ha etiquetat com a \#globalrevolution.

En aquests casos, els centres urbans triats per a la protesta trobaven en la seva naturalesa d'escenaris per a la confrontació social una de les claus de la seva centralitat simbòlica. És a ells als quals segments socials agreujats per una causa o una altra —o per moltes d'elles - acudien a expressar davant els poders i davant el conjunt de la societat les seves queixes i reclamacions. Aquests indrets de centralitat urbana veien així ressaltada la seva naturalesa de patrimoni social - és a dir, d'espais de proliferació i intensificació de sociabilitats - i com a barris històrics, és a dir, com a espais de i per a la història, el que és el mateix que dir per al conflicte. En aquests casos, les acampades es van guanyar el paper d'autèntiques entitats polítiques independents, amb vocació fins i tot constituent i que podien desenvolupar funcions interlocutores a través del sistema assembleari de què es dotaven (cf. Serrano-Moreno, 2013; Macpherson i 
Smith, 2013; Castañeda, 2012; Fuster Morella, 2012). L'interessant és que aquests campaments de protesta s'associaven íntimament als espais en què s'aixecaven, com si la veu que s'hi elevava a través de les assemblees no fos la dels congregats, sinó de l'espai mateix que omplien, aquestes places que trobaven en els seus ocupants el vehicle mitjançant el qual personificar-se i actuar, i no a l'inrevés. La plaça Sintagma a Atenes, la Tahrir al Caire, la Porta del Sol a Madrid, la plaça de Catalunya de Barcelona, la plaça Habima de Tel Aviv o Zucotti Park a Chicago, no eren mers receptacles o contenidors d'una contestació social, sinó entitats sobtadament vivificades que convertien els seus ocupants en instruments al servei d'una indignació que no era dels ciutadans, sinó del mateix indret urbà que s'ocupava.

\section{Una nova mística de l'espai públic}

Aquesta elevació de les places a personificació d'estats d'ànim compartits per una part important de la societat no es pot deslligar d'una idealització de l'espai públic que ha acompanyat el desenvolupament del que s'ha anomenat postpolítica, amb el seu projecte de superació de la lluita de classes i d'abandonament de les divisions ideològiques clàssiques en funció de nous llenguatges i nous paradigmes, un dels quals seria el ciutadanisme. El ciutadanisme és la ideologia de referència d'un conjunt de moviments de reforma ètica del capitalisme que aspira a alleujar els seus efectes mitjançant una agudització dels valors democràtics universals, i que considera que l'exclusió i l'abús no són factors estructurals, sinó mers accidents o contingències d'un sistema de dominació a què es creu possible millorar moralment (cf. Domínguez, 2011). El ciutadanisme no impugna el capitalisme, sinó els seus «excessos» i la seva manca d'escrúpols, crida a mobilitzacions massives destinades a denunciar determinades actuacions públiques o privades considerades injustes, però sobretot immorals, i ho fa proposant estructures d'acció i organització làbils, basades en sentiments - la indignació o la ràbia, per exemple - més que en idees, amb un èmfasi especial en la dimensió performativa i sovint fins $i$ tot festiva de l'acció pública. Prescindint de qualsevol referència a la classe social com a criteri classificatori, remet en tot moment a un difús ecumene 
d'individus als quals uneixen no els seus interessos, sinó els seus judicis morals de condemna o aprovació.

El ciutadanisme, més enllà del seu aspecte innovador, no deixa de ser una reedició del vell republicanisme reformista, per al qual l'espai públic no seria altra cosa que l'espacialització física d'un dels seus derivats conceptuals: l'anomenada societat civil. La ideologia ciutadanista és objecte de diverses interpretacions, algunes de les quals apareixerien fonamentant moviments i mobilitzacions hipercrítiques, ja que bé podria dir-se que ha acabat incorporant-se a l'instrumental teòric de les restes de l'esquerra històrica $\mathrm{i}$ fins $i$ tot dels sectors radicals que els mitjans oficials han etiquetat com a «antisistema». Però també el ciutadanisme està sent la doctrina oficial en què se sustenten polítiques, tant socialdemòcrates com conservadores, que fan l'elogi del tercer sector, la tasca de les ONG o d'una definició ben particular del capital social. Aquestes dues lectures en què es podria esquematitzar avui l'ús del ciutadanisme com a ideologia de referència es corresponen amb les dues versions que Mary Kaldor (2005: 21-24) reconeixia de la noció de «societat civil»: la neoliberal i la militant, aplicada aquesta última als corrents postmarxistes que aposten per un augment de la participació i l'autogestió i que reclamen una contínua activació de la ciutadania al marge de la política formal i amb vista a constituir-se en font permanentment de fiscalització i crítica dels poders governamentals i econòmics.

L'expressió actual d'aquest ciutadanisme militant la conformen sens dubte les grans mobilitzacions que s'han conegut al llarg i ample del planeta a principis de la dècada dels anys 10, i el paradigma seria potser el dels indignats espanyols del $15 \mathrm{M}$ en 2011 . No només com a indicatiu d'una reacció massiva i irada davant unes circumstàncies socials cada vegada més inacceptables, marcades per les retallades en l'atenció pública, els abusos financers i la corrupció política, sinó pel que ha implicat de recuperació del carrer com a escenari per a les lluites civils i d'incorporació o reincorporació de milers de persones a la discussió i l'acció polítiques. Ara bé, aquesta valoració positiva de la resposta popular davant els abusos del poder polític i econòmic no ha de ser incompatible amb una consideració ponderada de la naturalesa d'aquest tipus de moviments, que se centren en la vindicació d'una agudització dels valors abstractes de la democràcia; és a dir, en la potenciació d'una imaginà- 
ria ecumene igualitària basada en l'individu autònom, responsable i racional, agent lliure i conscient de la seva capacitat per propiciar tot tipus de canvis, pel que qualsevol altra identificació que no sigui la de ciutadà resulta improcedent.

Aquesta és la clau que explica el paper central concedit a l'espai públic segons el ciutadanisme radical, que no només pretén superar la interpretació dogmàtica del marxisme, sinó que desemboca a una autonomització dels moviments socials, un cop aquests han renegat del que va ser el seu paper subordinat $i$ dependent respecte de la lluita de classes i ja han renunciat a qualsevol eix de rotació durador i històricament transcendent. Per a la democràcia radical dels moviments indignats l'espai públic no és ja la comarca física accessible a tots, sinó el territori en el qual es desplega i es fa real l'esfera pública com l'arena de mediació independent tant de l'Estat com del mercat, en què tant insistí la filosofia política hegeliana. Per complir la seva missió de sòl d'una societat civil purificada i rejovenida, l'espai públic ha d'objectivar ara en aquest marc sensible que fins llavors havien estat simplement el carrer i la plaça, per fer-ne d'ells lloc físic de i per a l'«autèntica» civilitat; no la corrupta i adulterada actual, sinó, per fi, en tant que veritable àmbit autogestionat de discussió i acció, al si del qual l'individu viu no només el seu màxim nivell d'institucionalització política, sinó que es veu investit de tota la seva dignitat moral com fonament innegociable de la mística democràtica de l'obediència lliurement consentida.

Tenim, doncs, que el que fan els moviments socials de nou encuny és imposar una mutació essencial en la condició d'allò que fins llavors havien estat el carrer i la plaça com escenaris d'una sociabilitat singular entre estranys, que podien a voltes, col·ligats, exercir formes expeditives d'acció conjunta. De la mà de moviments com els dels indignats i els seus ecos, el que havia estat un simple però poderós marc ecològic d'activitat, l'espai urbà, es transmutava en el que pretenia ser entorn participatiu, moral i polític per al compromís democràtic, l'espai públic teòric del qual parlaren Arendt i Habermas, en el qual els presents podien i havien d'exercir les seves virtuts cíviques i la seva capacitat per assumir decisions vinculants a partir de la sobirania irrenunciable dels individus, seguint mecanismes d'acció pels quals la definició d'allò col·lectiu era difícil, per no dir impossible. Es confirmava així un canvi qualitatiu d'ex- 
traordinària importància: el carrer deixava de ser el vehicle d'expressió de les classes i els sectors en lluita, per, degudament mistificat, ser exaltat a la condició de temple a l'aire lliure on una rejovenida democràcia lliberal repetia les seves promeses incomplides i oficiava els seus vells misteris de reconciliació i consens entre classes.

\section{Referències}

Bolívar, E. (1996): «Circuitos ceremoniales y festivos en Medellín». Herrera, A. D. (Ed.): Ciudad y cultura. Memoria, identidad y comunicación (pp. 165-202), Universidad de Antioquía, Medellín.

Castañeda, E. (2012): «The Indignados of Spain: A Precedent to Occupy Wall Street», Social Movement Studies, 11 (3-4), 309-310.

Champagne, P. (1984): «La manifestation, la production de l'événement politique», Actes de la recherche en sciences sociales, 52-53, 19-41.

Collet, S. (1982): «La manifestation de rue comme production culturelle militante». Ethnologie française, XII (2): 167-77.

-(1988): «Les pratiques manifestantes comme processus révélateur des identités culturelles.» Terrain, 3, 56-58.

Delgado, M. (2006): «Morfología urbana y cambio social», Bergalli, A. R. i I. Rivera (Eds.): Emergencias urbanas (pp. 133-169). Anthropos, Barcelona.

Delgado, M. (Dir.) (2004): Carrer, festa i revolta. Els usos simbólics de l'espai públic a Barcelona (1951-2000), Departament de Cultura, Generalitat de Catalunya, Barcelona.

Domínguez, M. (2011): Ciudadanismo y postpolítica, Federación de Estudiantes Libertarios, Somosaguas.

Favre, P. (Ed.) (1990): La manifestation, Presses de la Fondation National des Sciences Politiques, Paris.

Fillieule, O. (1993) : Sociologie de la protestation. Les formes de l'action collective dans la France contemporaine, L'Harmattan, Paris.

Fillieule, O. i D. Tartakovsky (2008): La manifestation, Presses de Sciences Po, Paris.

Fuster Morella, M. (2012): "The Free Culture and 15M Movements in Spain: Composition, Social Networks and Synergies», Social Movement Studies: Journal of Social, Cultural and Political Protest, 11 (3-4): 386-392. 
Iglesias Turrión, P. (2005): «Un nuevo poder en las calles. Repertorios de acción colectiva del Movimiento global en Europa. De Seattle a Madrid», Política y Sociedad, 42/2: 63-93.

KALdor, M. (2005): La sociedad civil global, Tusquets, Barcelona.

Kertzer, D. I. (1992): «Rituel et symbolisme politiques des sociétés occidentales», L'Homme, Xxxi (1), 79-90.

López SÁnchez, P. (1993): Un verano con mil julios y otras estaciones. Barcelona: de la Reforma Interior a la Revolución de Julio de 1909, Siglo XXI, Madrid.

Macpherson, R i D. A. Smith (2013): «Occupy as a World Anti-Systemic Movement», Peace Review, 25g (3): 367-375.

Serrano-Moreno, J. E. (2012): «Ethnographie de l'acampada. La politisation à marche forcée de la génération perdue», Multitudes, 50: 75-79.

Tilly, Сн. (1978): From Mobilization to Revolution, University of Michigan, Chicago.

- (2005): «Los movimientos sociales entran en el siglo veintiuno», Política y Sociedad, 42 (2): 11-35.

Traugott, M. (2003): Protesta social. Repertorios y ciclos de acción colectiva, Hacer, Madrid. 
